African J. Biol. Sci., 15 (1): 137-153 (2019)

ISSN 1687-4870

www.aasd.byethost13.com

e- ISSN 2314-5501 (online)

e.mail: aasdjournal@yahoo.com

\title{
Enhancement of Antibiotics activity by microbially synthesized silver nanoparticles
}

\author{
Mahmoud A. Abushiba ${ }^{1}$, Gamal M. El-Sherbiny' ${ }^{2}$, Saad A.M. Moghannem², Mohamed H. \\ Kalaba $^{2}$, Einas H. El- Shatoury ${ }^{3}$ and Ali M. Saeed ${ }^{3}$ \\ 1-Department of Biology, Faculty of Science, Azzaytuna University, Tarhuna, Libya. \\ 2- Department of Botany and Microbiology, Faculty of Science (Boys), Al-Azhar University, \\ Cairo, Egypt. \\ 3 -Department of Microbiology, Faculty of Science, Ain Shams University, Cairo, Egypt.
}

\begin{abstract}
Biological synthesis of nanoparticles is a promising approach that is comparatively inexpensive and eco-friendly. Among various microorganisms, actinobacteria have been found to be efficient in the synthesis of nanomaterials. In thisstudy, extracellular biosynthesis of silver nanoparticles (Ag-NPs) was investigated by mixing silver nitrate with culture filtrate of Streptomyces rochei strain MFA-37. The biosynthesized Ag-NPs were characterized by UV-Vis spectrophotometric analysis, and showed a peak of absorbance at $440 \mathrm{~nm}$. Fourier transform infrared (FTIR) analysis showed amines and amides that are responsible for the stabilization of Ag-NPs. The morphology and size of nanoparticles were determined using high-resolution transmission electron microscopy, XRD and DLS techniques which indicated well dispersed, spherical Ag-NPs sized 2-20 nm, and the zeta potential of AgNPs reached $-20.5 \mathrm{mV}$. Enhancement of antibacterial activity of fourteen antibiotics was conducted by combining antibiotics with synthesized AgNPs. The synergistic activities of AgNPs combination with antibiotics were determined using disc diffusion against two multi-drug resistant Staphylococcus aureus SA-185 and SA-325 recovered from Libya. The highest synergistic effects were 6.11 and 6.37 folds for Penicillin followed by 6.11 and 4.44 folds for Ciprofloxacin and 6.11 and 3.69 folds for Erythromycin for MRSA-185 and MRSA-325, respectively. This activity of AgNPs and antibiotics could be valuable for the manufacture of hybrid drugs to kill or inhibit the MRSA infection especially in case of superficial injuries.
\end{abstract}

Key words: MRSA, Ag-NPs, Antibiotics, synergistic effects.

\section{INTRODUCTION}

The widespread use of antibiotics to treat bacterial infections has resulted in the emergence of resistant forms of these organisms. Particularly, methicillin-resistant S. aureus (MRSA) which is a major concern, as it reduces the antibiotic treatment options for both prevention and cure and ultimately lead to prolonged patient hospitalization, increased mortality and treatment costs (Iram et al., 2015). Its remarkable ability to acquire antibiotic resistance has contributed to its emergence as an important pathogen in a variety of settings (Daini \& Akano, 2009). So, studies are greatly required in finding out new antimicrobial agents against methicillin resistant Staphylococcus aureus (MRSA).One of the promising methods for overcoming bacterial resistance is the use of metallic nanoparticles (Allahverdiyev et al., 2011). Ag-NPs are well known for their striking antimicrobial activity, and most of the synthesized Ag-NPs exhibit their major application as an anticancer, antioxidant and antimicrobial agents (Składanowski et al., 2017). Unfortunately, convenient chemical and physical techniques have several 


\section{Mahmoud A. Abushiba et al.}

disadvantages, such as the use of toxic chemicals, high energy requirements, and difficult purification steps (Begum et al., 2009). Biological synthesis of metal nanoparticles has been well achieved by various microorganisms (Golinska et al., 2014; Zarina \& Nanda, 2014). Actinobacteria are considered as an important resource for new products of medical and industrial interest such as antimicrobial agents (Bhosale et al 1., 2015; Mohamedin et al., 2015). Streptomyces sp is one of the genera of Actinobacteria, an efficient producer of bioactive compounds like antibiotics and nanoparticles which can be formed extracellularly and intracellularly, with a wide range of activities (Karthik et al., 2014; Lakshmi et al., 2015). The growing resistance of pathogenic bacterial strains to traditional antibacterial treatments has encouraged alternate strategies to control infections. One of these alternative strategies is combinatorial therapy, the combination of antibiotics and metal nanoparticles has numerous benefits that include increase the antibiotics' efficacy against resistant pathogens (Li et al., 2005; Fayaz et al., 2010). Moreover, nanoparticleantibiotic combinationlowers the amount of both agents in the dosage, which reduces toxicity and increases antimicrobial properties. Additionally, due to this combination, the concentrations of antibiotics were increased at the place of antibiotic-microbe contact and thus accelerated the binding between microbes and antibiotics preventing need for long term antibiotic use, prevent emergence of multidrug resistant bacteria (Allahverdiyev et al., 2011).Up till now few reports are available on synergistic bactericidal activity of inorganic nanomaterials in combination with beta lactam antibiotics as penicillin and to the best of our knowledge synergistic activity of AgNPs nanoparticles with penicillin have not yet been thoroughly investigated. In this article, we attempted to synthesize, characterize, and evaluate antimicrobial activity of Ag-NPs synthesis using Streptomyces rochei strain MFA-37 isolated from Egypt, moreover study synergistic effect of Ag-NPs combined with antibiotics against multidrug-resistant Staphylococcus aureus recovered from Libya.

\section{MATERIALS AND METHODS Soil sample collection and isolation of actinobacteria}

Soil samples were collected from cultivated soil in Dakahleya, Egypt during April $2017.20 \mathrm{~g}$ of the soil was air-dried for 3 days at room temperature.Isolation and purification of Actinobacteria isolates were performed according to Tsao et al. (1960).

\section{Screening of Ag-NP synthesizing actinobacteria}

The preparation of cell-free supernatant and the biosynthesis of Ag-NPs were performed according to El-Naggar et al. (2016). The biosynthesis of AgNPs can be inferred by a color change from pale yellow into brown colorand confirmed with UVvisible absorbance of the reaction mixture in the $300-600 \mathrm{~nm}$ range (El-Naggar et al., 2016). The potent isolate selected for further characterization.

\section{Characterization of the selected actinobacterial isolate}

The selected isolate MFA-37 was characterized by light microscope (Optika, Italy) using slide culture technique and transmission electron microscopy (JEOL Technics Ltd, Japan) at the Regional Center for Mycology and Biotechnology, Al-Azhar University, Cairo. It was also characterized physiologically and biochemically according to (Holt et al., 1994). Molecular identification was done using 16S rDNA analysis according to Atta et al. (2011). 


\section{Enhancement of Antibiotics activity by microbially synthesized silver nanoparticles}

\section{Biosynthesis and purification of silver nanoparticle}

Ag-NPs was prepared as mentioned above using the supernatant of the selected strain MFA-37. The silver ions reduction was indicated via visual observation of color and by monitoring the UV-Vis spectra (Abd-Elnaby et al., 2016). The obtained of Ag-NPswas purified by centrifuged and washed with deionized water,the $\mathrm{Ag}$ NPswere dried using a hot air oven at $60^{\circ} \mathrm{C}$ until a constant weight was obtained (Singh et al., 2013).

\section{Characterization of Ag-NPs}

The opto-electronic properties of the biosynthesized Ag-NPs were measured by ultraviolet-visible absorption spectra (UVvis, Hitachi U-2800) in the range of 200$800 \mathrm{~nm}$. The Fourier transform infrared spectroscopy (FTIR) spectrum of the sample was recorded on a on Agilent system Cary 630 FTIR model -Chemistry Department, Faculty of Science, Al-Azhar University, Cairo, Egypt, in the range $400-4,000 \mathrm{~cm}-1$ in FT- IR spectroscopy at a resolution of 1 $\mathrm{cm}^{-1}$.The spectral data obtained were compared with the reference chart to identify the functional groups present in the sample. The size and shape of the products were observed by High-resolution transmission electron microscopic (HRTEM) (JEOL 2100 Japan, at National Research Center (NRC), Giza, Egypt).The crystalline structure of the biosynthesized AgNPs was characterized by X-Ray diffraction that was carried out using the Shimadzu apparatus with nickel-filter and $\mathrm{Cu}-\mathrm{Ka}$ target, Shimadzu Scientific Instruments (SSI), Kyoto, Japan. The particle size distribution of AgNPs was evaluated using Dynamic Light Scattering (DLS) measurement conducted with a Malvern Zetazier Instrument. Measurements were taken in the range between 0.1 and
$1000 \mu \mathrm{m}$. Data obtained were analyzed using Zetasizer software.The XRD and DLS were measured at the National Center for Radiation Research and Technology (NCRRT), Cairo, Egypt. Zetasizer Nano ZS, Malvern, UK was used to characterize the zeta potential of the nanoparticles in the solution. Data were obtained and analyzed using Zetasizer software, samples were examined at Nawah-Scientific center, Almokattam, Cairo, Egypt. Generally, Characterization of AgNPs were carried out according to (Anandalakshmi et al., 2016).

\section{Antibacterial activity of AgNPs}

Multidrug resistant Staphylococcus aureus isolates were recovered from Tripoli University Hospital, Tripoli, Libya and coded as AS-185 andSA-325. The identification and antibiotic sensitivity were carried out for these isolates by Biomerux VITEK2 automated system Version 05.04 (BioMérieux Inc.) at microbiology laboratory, Tripoli university hospital. Stock solution of biosynthesized $\mathrm{Ag}-\mathrm{NPs}(5 \mathrm{mg} / \mathrm{ml})$ was prepared in distilled water then the antibacterial activity was determined against MDR S. aureus AS-185 andSA-325. This assay was performed using agar well diffusion technique, in which, wells $(8 \mathrm{~mm})$ were cut in Muller Hinton agar (Merck KgaA, Germany) plates inoculated with tested bacteria. Fifty microlitres of AgNPs solution were pipetted into each well. After incubation at $37{ }^{\circ} \mathrm{C}$ for $24 \mathrm{~h}$, the inhibition zone diameter around each well was measured in mm Antibiotic paper disks of Penicillin and vancomycin were used for comparison in this assay that was carried out according to Kirby-Bauer method according to (Bauer et al., 1966; Moghannem et al., 2017).

Assessment of AgNPs synergistic activity in combination with antibiotics 
Mahmoud A. Abushiba et al.

To determine the synergistic effect of AgNPs in combination with antibiotics, different antibiotics belong to different classes of antibiotics: Amoxicillin, Amoxicillin- clavulanate, Cefoxitin, Cefuroxime, Ciprofloxacin, Erythromycin, Gentamicin, Methicillin, Nalidixic acid, Neomycin, Oxacillin, Penicillin, Polymexin $\mathrm{B}$, and Tetracycline were used. A disc diffusion method was performed to screen the synergistic activity of AgNPs and antibiotics. All antibiotics were used in the form of standard antibiotic discs $6 \mathrm{~mm}$ in diameter (HiMedia Laboratories Pvt. Ltd, Mumbai, Maharashtra, India). Bacterial suspension of MDR S. aureus AS-185 andSA-325 were spread on MHA plates then, standard antibiotic disk was impregnated with $25 \mu \mathrm{l}$ of prepared AgNPs $(0.25 \mathrm{mg} / \mathrm{ml})$ and gently placed on the MHA plates as well as standard antibiotic disk without AgNPs and impregnated paper disk at the same concentration. After $48 \mathrm{~h}$ of incubation at $37{ }^{\circ} \mathrm{C}$, the inhibition zone $(\mathrm{mm})$ was measured. This assay was performed in triplicate and the increase in fold area was estimated by measuring the mean of the inhibition zone produced by an antibiotic alone and in combination with AgNPs, according to the following equation:

The fold increase area $=\frac{\left(B^{2}-A^{2}\right)}{\left(A^{2}\right)}$

Where $\mathbf{A}$ is ZOI for the antibiotic and $\mathbf{B}$ is ZOI for the antibiotic + Ag-NPs (Birla et al., 2009).

RESULTS AND DISCUSSION Isolation and Screening of Actinobacteria for Extracellular biosynthesis of AgNPs
Actinobacterial isolates were recovered from soil samples and purified by streaking on SNA medium. These isolates were screened for extracellular biosynthesis of Ag-NPs. According to this screening, the isolate MFA-37 was selected. The color of reaction mixture changed from light yellow to dark brown at end of incubation time. No color change was observed during incubation of both silver nitrate solution and cell free supernatant without $\mathrm{AgNO}_{3}$ (Fig. 1A \& 1-B). The UV- Visible spectra of silver nitrate solution, cell free supernatant of actinobacterial isolate MFA-37 and reaction mixture were completely different and the reaction mixture of AgNPs wasseemed the highest absorbance at 400$450 \mathrm{~nm}$ (Fig. 2).

The change in color of the reaction mixture may attributed to the reducing and capping potential substances present in the cell free supernatant of actinobacterial isolate MFA-37. The brown color of the AgNPs is due to excitation of surface plasmon vibration in Ag-NPs (Phanjom \& Ahmed, 2015). It is observed from Figure (1-C) that the synthesized AgNPs display a clear and single surface plasmon resonance (SPR) peak located at $400-450 \mathrm{~nm}$ which confirms the reduction of silver ion to metallic silver. Metal nanoparticles have free electrons, which yield a surface plasmon resonance (SPR) absorption band, due to the mutual vibration of electrons of metal nanoparticles in resonance with light wave. The appearances of the peaks show the characteristics of surface plasmon resonance of Ag-NPs (Anandalakshmi et al., 2016). 
African J. Biol. Sci., 15 (1): 137-153 (2019)

ISSN 1687-4870

www.aasd.byethost13.com e- ISSN 2314-5501 (online)

e.mail: aasdjournal@yahoo.com

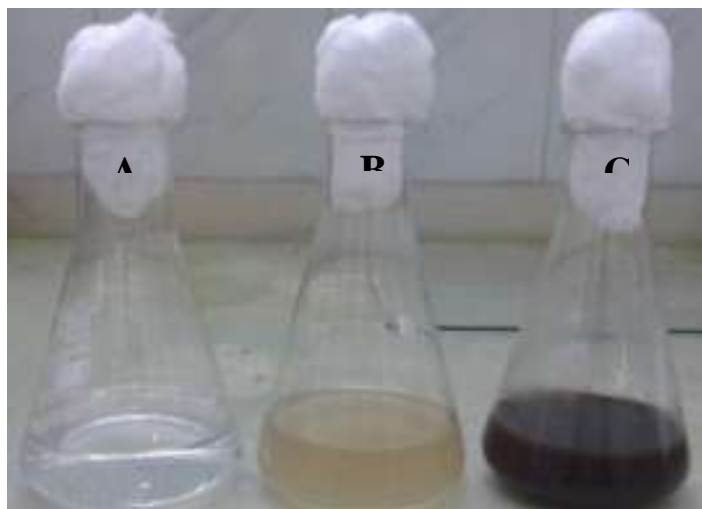

Fig. (1): Photographs of biosynthesis of silver nanoparticle(A): $\mathrm{AgNO}_{3}$, (B): cell free supernatant of actinobacterial isolate MFA-37, and (C): reaction mixture after $24 \mathrm{~h}$.

\section{Characterization of actinobacterial isolate} MFA-37

Morphological characteristics

Microscopic examination of actinobacterial isolate MFA-37 grown on SNA medium at $28^{\circ} \mathrm{C}$ for 7 days (Fig. 3-A) using slide culture technique indicated that, aerial mycelium was long rectiflexibile to spiral with open loop bearing spore chain. Transmission electron microscopy was confirmed that, each spore chain contains more than 30 cylindrical spores with smooth surface (Fig. 3-B and 3-C).

\section{Culture characteristics}

Culture characteristics of isolate MFA-37were noted after their cultivation on different International Streptomyces Project (ISP) media. This isolate was grown well on ISP-3, ISP-5, ISP-7 and SNA media while the growth on ISP-2, ISP-4 and ISP-6 was moderate. It produced white to grey powdery colonies on the surface of agar while reversed side varied between light yellow to brown without diffusible pigment on all ISP and SNA media (Table 1).

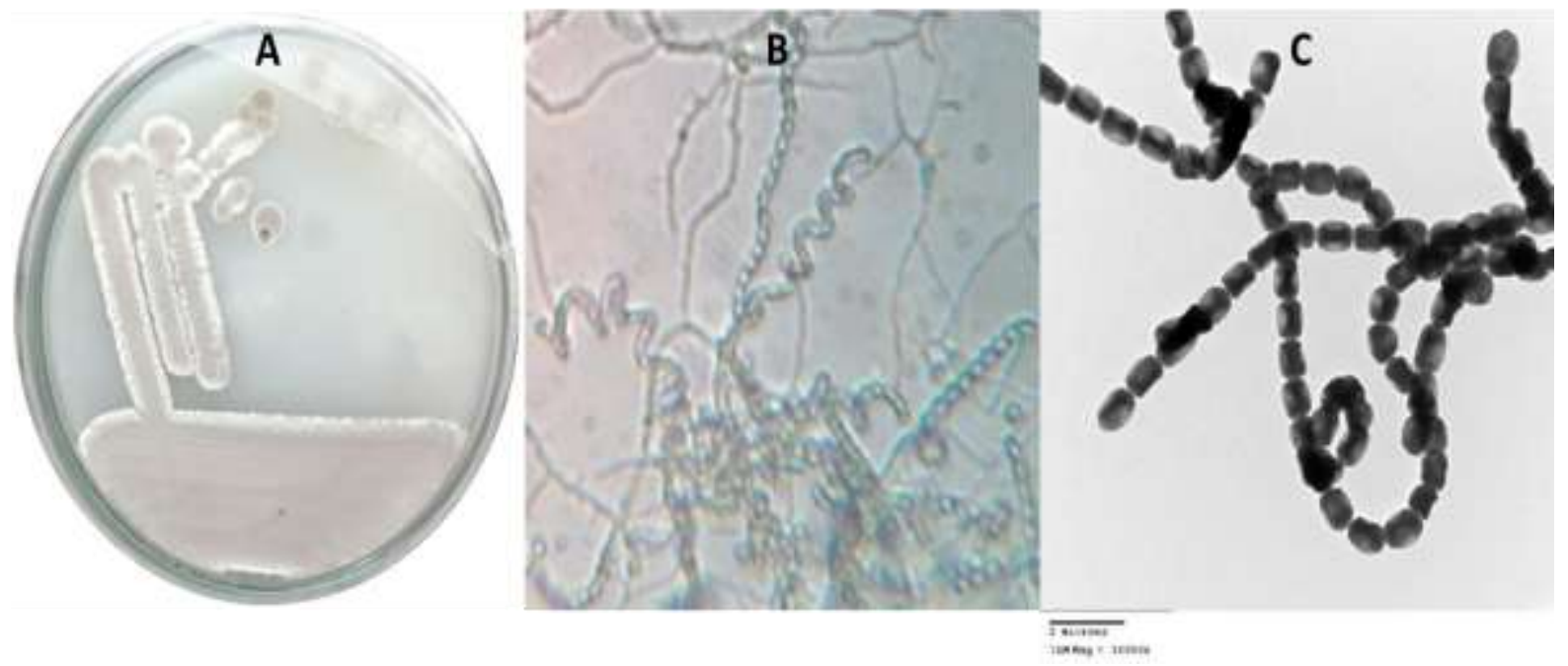


Mahmoud A. Abushiba et al.

Fig.(3):photograph of culture isolate MFA-37 on SNA medium(A), Spore chain bearing hyphae by light microscopy (X800) (B) and Spore chain arrangement and spore surface by TEM; (X10000) (C).

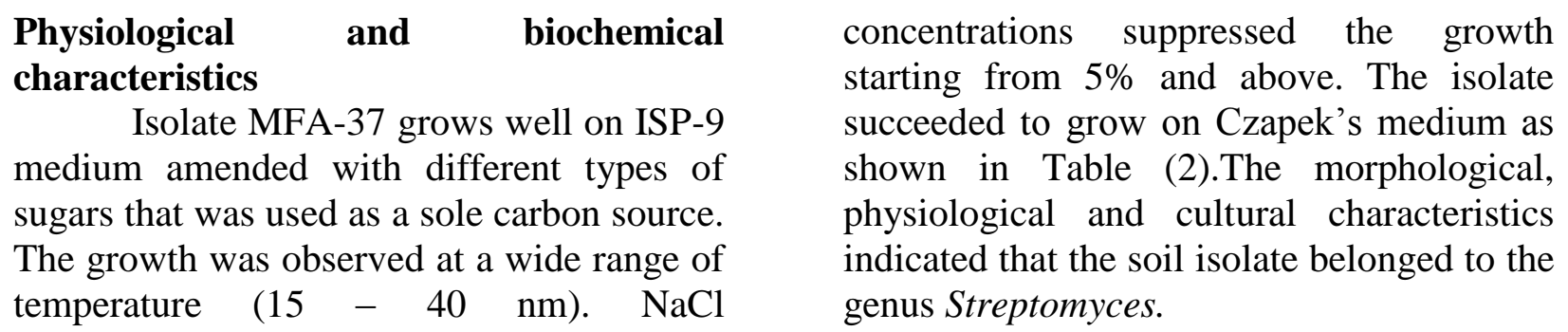

Table 1:Culture characteristics of isolate MFA-37on different ISP media

\begin{tabular}{|c|c|c|c|c|}
\hline Medium & $\begin{array}{c}\text { Aerial } \\
\text { mycelium }\end{array}$ & $\begin{array}{l}\text { Substrate } \\
\text { mycelium }\end{array}$ & $\begin{array}{c}\text { Diffusible } \\
\text { pigment }\end{array}$ & $\begin{array}{l}\text { Growth } \\
\text { density }\end{array}$ \\
\hline $\begin{array}{l}\text { Yeast extract malt extractagar medium } \\
\text { (ISP-2) }\end{array}$ & White & Brown & No & Moderate \\
\hline Oatmeal agar medium (ISP-3) & Grey & Light yellow & No & Good \\
\hline Inorganic salts starch agarmedium (ISP-4) & White & Yellow & No & Moderate \\
\hline $\begin{array}{l}\text { Glycerol - asparagine agarmedium (ISP- } \\
\text { 5) }\end{array}$ & Grey & Light brown & No & Good \\
\hline $\begin{array}{l}\text { Peptone yeast extract ironagar medium } \\
\text { (ISP-6 }\end{array}$ & Creamy & Light brown & No & Moderate \\
\hline Tyrosine agar medium (ISP-7) & White & Brown & No & Good \\
\hline Starch nitrate agar (SNA) & Grey & Light brown & No & $\begin{array}{l}\text { Very } \\
\text { good }\end{array}$ \\
\hline
\end{tabular}

\section{Molecular characterization}

The molecular identification of isolate MFA-37 using 16s rRNA gene was performed. The small subunit of rRNA (16S) was amplified using universal primers RW01 and DG74 and sequenced resulting in partial nucleotide sequences of $480 \mathrm{bps}$. The obtained sequence of isolate MFA-37 was compared with available $16 \mathrm{~S}$ rDNA sequences in the Gen Bank databases using BLASTn tool and the present data referred to that, the isolate MFA-37 belonged to genus Streptomyces with greatest homology (97\%) to $S$. rochei published sequences. The partial sequence of $16 \mathrm{~S}$ rDNA of isolate MFA37 was deposited in Gen Bank under the accession number MH577306.A multiple sequence alignment was constructed between the isolate MFA-37 and reference strains. Phylogenetic analysis was performed by construction of phylogenetic tree using a neighbor joining method to describe the relationships among all Streptomyces isolates (data not shown). 
African J. Biol. Sci., 15 (1): 137-153 (2019)

ISSN 1687-4870

www.aasd.byethost13.com e- ISSN 2314-5501 (online)

e.mail: aasdjournal@yahoo.com

Table 2:Physiological and biochemical characteristics of isolate MFA-37

\begin{tabular}{|c|c|c|c|}
\hline Characteristics & Results & Characteristics & Results \\
\hline \multicolumn{2}{|l|}{ Utilization of carbon sources } & \multicolumn{2}{|c|}{ Growth at different temperatures $\left({ }^{\circ} \mathrm{C}\right)$} \\
\hline D- Glucose & ++ & 15 & + \\
\hline L-Rhamnose & + & 20 & + \\
\hline D-Xylose & ++ & 25 & ++ \\
\hline Mannitol & + & 30 & ++ \\
\hline Inositol & - & 35 & + \\
\hline Sucrose & \pm & 40 & + \\
\hline Arabinose & + & 45 & - \\
\hline Cellulose & - & \multicolumn{2}{|c|}{ Growth at different concentration of $\mathrm{NaCl}(\%)$} \\
\hline Fructose & ++ & $1 \%$ & ++ \\
\hline Starch & ++ & $2 \%$ & ++ \\
\hline \multicolumn{2}{|l|}{ Utilization of amino acids } & $3 \%$ & ++ \\
\hline Lipid hydrolysis & + & $4 \%$ & + \\
\hline Starch hydrolysis & + & $5 \%$ & - \\
\hline Casein hydrolysis & + & $6 \%$ & - \\
\hline Urea degradation & + & $7 \%$ & - \\
\hline Catalase & + & $8 \%$ & - \\
\hline Oxidase & + & $9 \%$ & - \\
\hline Growth on czapek's medium & + & $10 \%$ & - \\
\hline
\end{tabular}

“+” indicate Positive, “-” Negative, “ \pm " doubtful results, "+" moderate growth “++" good growth

The resulted sequence was aligned with available almost compete sequence of type strains of family streptomycetacae. It formed separate clade that was closely related to Streptomyces rochei strain NRRL B-1559 sharing 16s rRNA gene similarity matrix is $97 \%$ with this species and others but, the results of microscopic, physiological and biochemical characteristics of isolate MFA-37 suggest that this isolate is Streptomyces rocheistrain MFA-37 according to Hensyl (1994).

\section{Characterization of Ag-NPs}

\section{Ultra Violet-Visible (UV-Vis) Spectroscopy}

The biosynthesized AgNPs were characterized by UV-visible spectroscopy, which has been shown to be a valuable and important tool for the analysis of metal nanoparticles. In the UV- visible spectrum, a strong, broad peak at about $440 \mathrm{~nm}$ was observed for AgNPs indicating the presence of AgNPs (Fig. 4). In agreement with previous reports, the absorption peak between 400 and $450 \mathrm{~nm}$ clearly indicates the formation of Ag-NPs and this due to the excitation of plasmon resonance (Manikprabhu \& Lingappa, 2013; and Kumar et al., 2015). 
African J. Biol. Sci., 15 (1): 137-153 (2019)

ISSN 1687-4870

e- ISSN 2314-5501 (online)

www.aasd.byethost13.com

e.mail: aasdjournal@yahoo.com

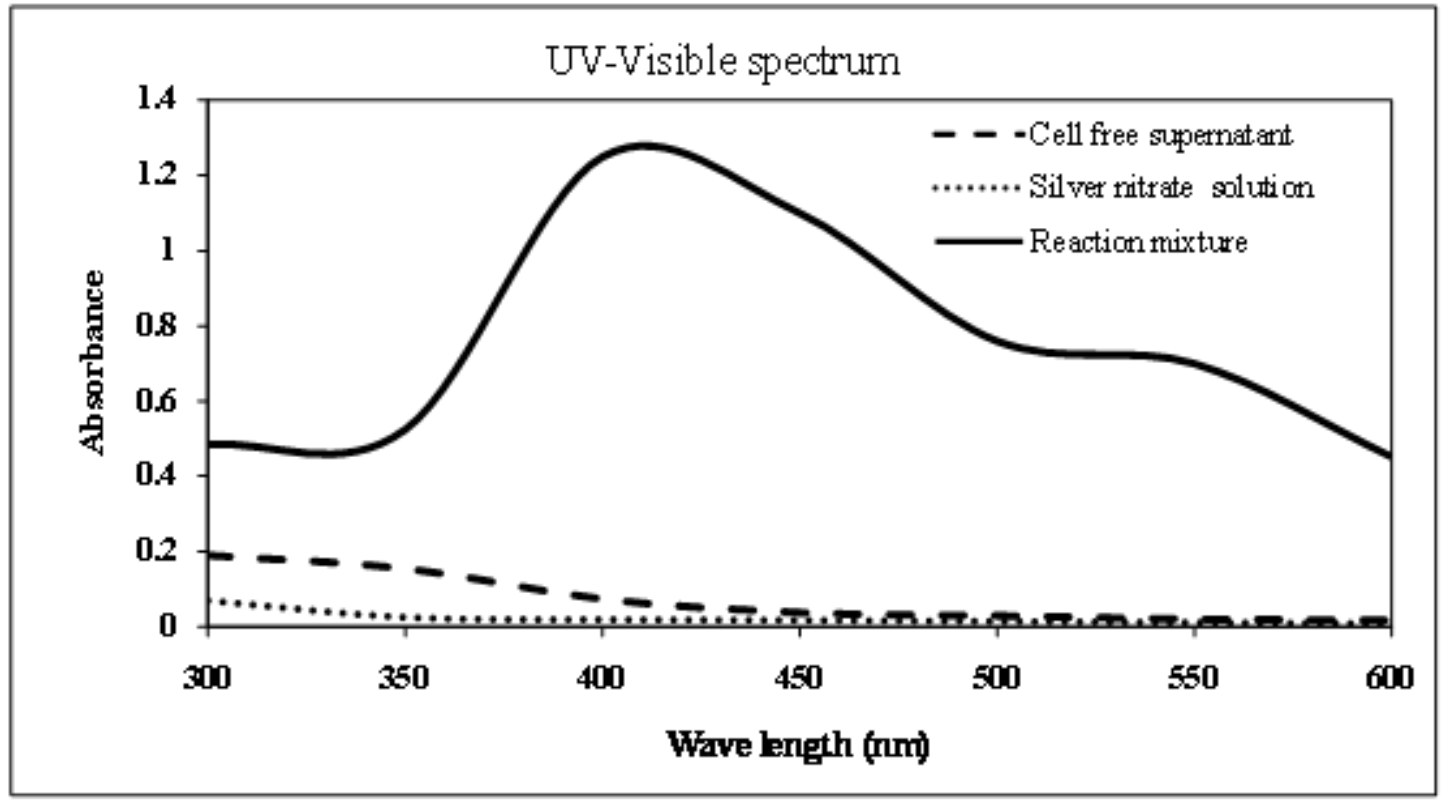

Fig. (4): The UV/V is spectrum of the Ag-NPs synthesized byStreptomyces rochei strain MFA-37.

\section{Fourier Transform Infrared (FTIR) Spectroscopy analysis}

The FTIR analysis was used for the characterization of AgNPs in cell free filtrate Streptomyces rochei strain MFA37.FTIR assessment revealed the ranges between 400 to $4000 \mathrm{~cm}^{-1}$ (Fig. 5). The IR analysis showed the following: the sharp peaks at $3448.7 \mathrm{~cm}^{-1}$ were indicative of the $\mathrm{N}-\mathrm{H}$ stretching of amides, the peak at 1635.6 $\mathrm{cm}-1$ were attributed to the $\mathrm{N}-\mathrm{H}$ bending of amines, the peak at $1396.4 \mathrm{~cm}^{-1}$ was ascribed to the NO2 asymmetric stretching of nitro compounds, the peak at 1087.85 $\mathrm{cm}-1$ was attributed to the C-N stretching of amines, the peak at $1087.8 \mathrm{~cm}^{-1}$ was attributed to the $\mathrm{C}-\mathrm{N}$ stretching of amines and $563.21 \mathrm{~cm}^{-1}$ (C-Br stretch of alkyl halides).FTIR were carried out to identify the biomolecules for capping and efficient stabilization of the metal nanoparticles synthesized. From the analysis of FTIR studies we concluded that the amide and amine groups from the amino acid residues and proteins have the stronger ability to bind metal to prevent agglomeration and thereby stabilize the medium. This suggests that the biological molecules could possibly perform dual functions of formation and stabilization of Ag-NPs in the aqueous medium (Majeed et al., 2016). 
African J. Biol. Sci., 15 (1): 137-153 (2019)

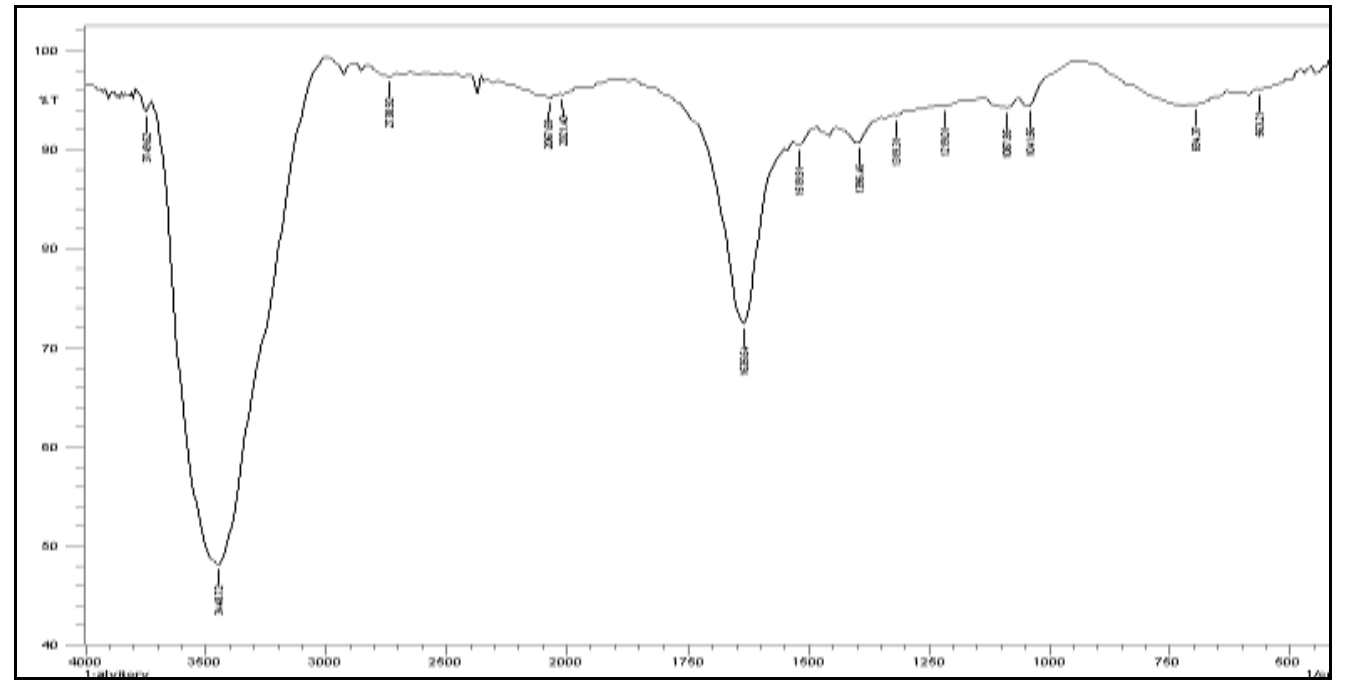

Fig. (5): The FTIR spectrum of the Ag-NPs synthesized byStreptomyces rochei strain MFA-37.

Size and morphology analysis of AgNPs using HR-TEM

HR-TEM micrographs of the biosynthesized AgNPs revealed distinct, uniformly crystalline and a quasi-spherical structure of the Ag-NPs in the reaction solution. These nanoparticles were well separated from each other. The average particle size was estimated from measuring particles representing different size from TEM images and showed particle sizes between 2 and $20 \mathrm{~nm}$ (Fig. 6).

Several reports revealed that, the extracellular biosynthesized AgNPs are predominantly spherical in shape (Raut et al., 2009; ; Deepa et al., 2013) reported that Ag-NPs synthesized from marine Actinobacteria shows size of nanoparticles ranging from 20 to $30 \mathrm{~nm}$.

\section{X-ray diffractometry}

The crystalline nature of biosynthesised Ag-NPs was analysed using powder X-Ray diffractometer. This method was used to confirm the particles as silver and identify the phase composition, crystalline structure and size of the biosynthesized Ag-NPs (Daphedar \& Taranath, 2018).The data represented in (Fig. 7) show the XRD pattern of Ag-NPs. The pattern clearly shows the main peaks at $2 \theta 38.19, \quad 44.37, \quad 64.56$ and 77.47 corresponding to the (111), (200), (220) and (311) planes, respectively. By comparing JCPDS (file no: 89-3722), The XRD pattern thus clearly illustrates that the Ag-NPs formed in this present synthesis are crystalline in nature and having face centred cubic (fcc) crystal structure. The average crystalline size of the Ag-NPs was determined, and their average size found to be $14 \mathrm{~nm}$. 
African J. Biol. Sci., 15 (1): 137-153 (2019)

ISSN 1687-4870

www.aasd.byethost13.com e- ISSN 2314-5501 (online)

e.mail: aasdjournal@yahoo.com

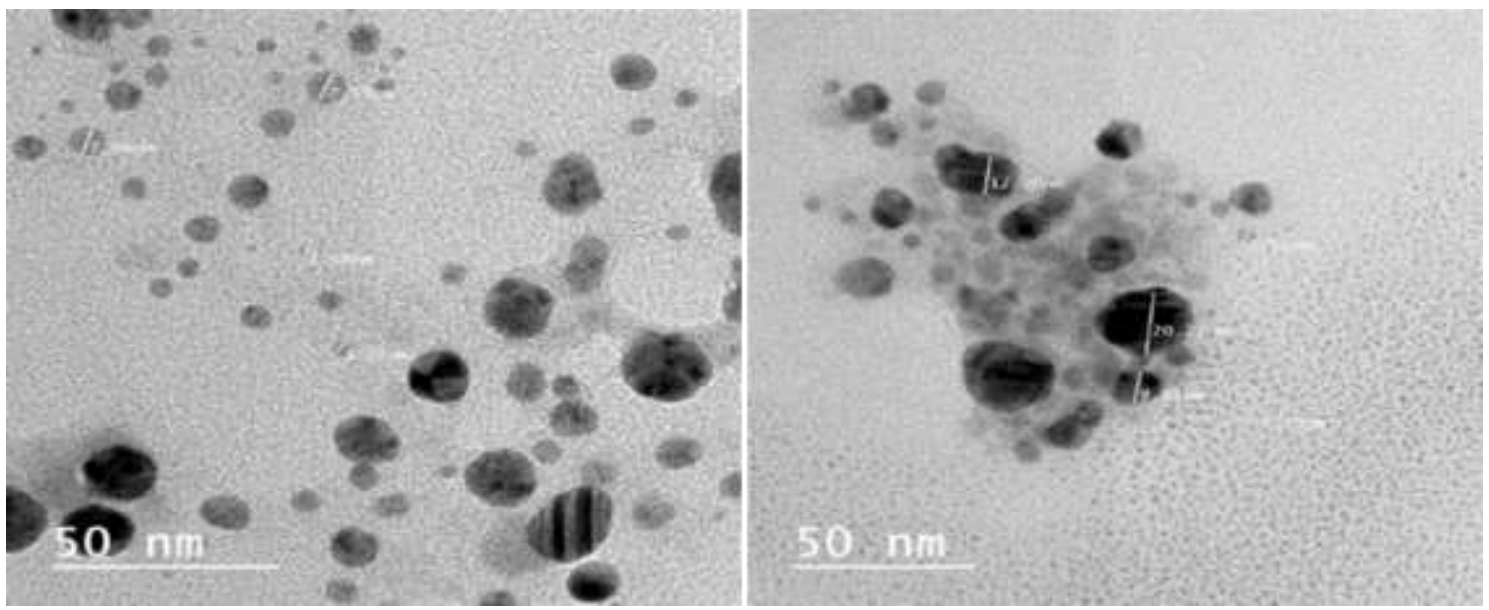

Fig. (6):HR-TEM image of the AgNPs formed by the reaction of $1 \mathrm{mM}$ AgNO3 and the cellfree supernatant of Streptomyces rochei strain MFA-37, Scale bar $=50 \mathrm{~nm}$.

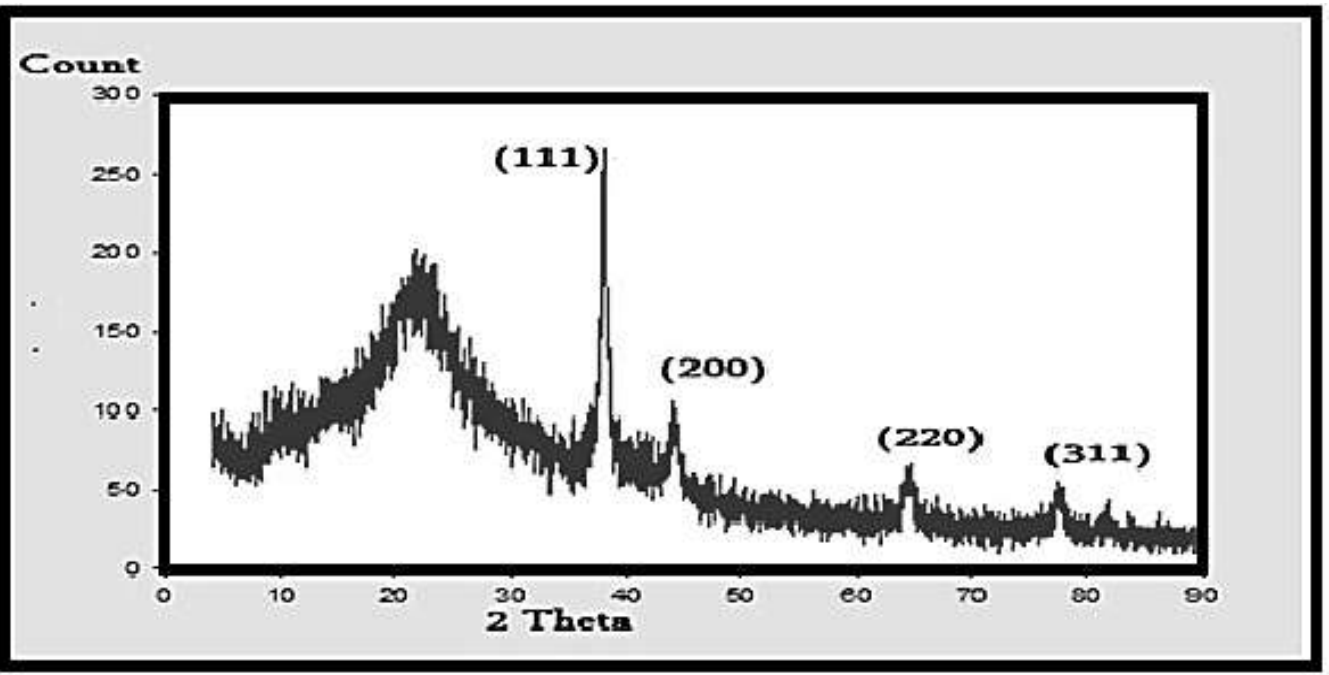

Fig. (7):XRD pattern of synthesized Ag-NPs by Streptomyces rochei strain MFA-37.

\section{Particle size distribution}

Dynamic light scattering (DLS) is a valuable technique to evaluate particle size, and size distribution of nanomaterials in solution. DLS was carried out to determine particle size in aqueous solutions and Laser diffraction studies revealed that particle size obtained from DLS were monodisperse in nature and are in the range of $14.2 \pm 1.6 \mathrm{~nm}$ (Fig. 8). Saha et al. (2010)reported that the particle size distribution of Ag-NPs synthesized by phytopathogenic fungus Bipolaris nodulosa using its mycelia free media shows that particles are monodisperse mixture, with particle size $10-60 \mathrm{~nm}$. 
African J. Biol. Sci., 15 (1): 137-153 (2019)

ISSN 1687-4870

e- ISSN 2314-5501 (online)

www.aasd.byethost13.com

e.mail: aasdjournal@yahoo.com

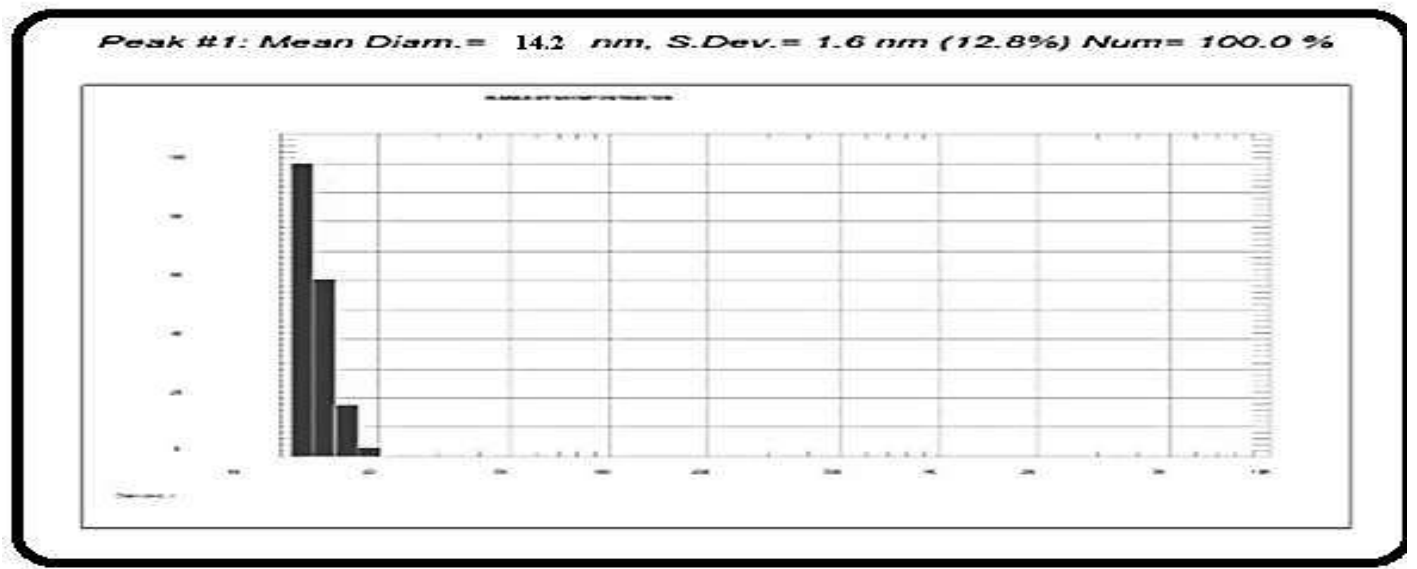

Fig.(8): DLS pattern of synthesized Ag-NPs by Streptomyces rochei strain MFA-37.

\section{Potential measurement}

The zeta potential value is the total number of charges of the functional group with a negative charge on the surface of AgNPs (Borase et al., 2013). In this study, the zeta potential value of the dispersed AgNPs in distilled water recorded $-20.5 \mathrm{mV}$ as shown in Figure (9). This value indicates thatAgNPs produced in this study are stable, and suitable for long-term storage, and with this charge also became more dispersed and were difficult to agglomerate.and this similar to finding by Jinmeng et al. (2017) who indicate that the potential value of AgNPs that was synthesized from rice straw biomass was $-21.2 \mathrm{mV}$ and they concluded that those nanoparticles charge made it good stable and suitable for long-term storage and the higher absolute value is made nanoparticles in suspension more stability.

\section{Antibacterial activity of AgNPs}

In the present investigation, the antibacterial activity of biosynthesized
AgNPs was determined against MDR $S$. aureus SA-185 and SA-325 clinical isolate by agar diffusion method. The results indicated that AgNPs exhibited antibacterial effect with inhibition zone $(22 \mathrm{~mm})$ also vancomycin showed an inhibition zone of 22 $\mathrm{mm}$, on the other hand, penicillin seemed as ineffective against both isolates (Fig. 10).

The formation of inhibition zone around the well was an indication of antibacterial activity of Ag-NPs (Narasimha et al., 2013). Both vancomycin and penicillin were used as positive and negative control respectively to compare their action with the action of biosynthesized AgNPs against this clinical isolate. The selection of these two types of antibiotics was done according to their antibiotic profile which determined manually and automatically using paper disc agar diffusion method and vitek2 system respectively. 
African J. Biol. Sci., 15 (1): 137-153 (2019)

ISSN 1687-4870

www.aasd.byethost13.com e- ISSN 2314-5501 (online)

e.mail: aasdjournal@yahoo.com

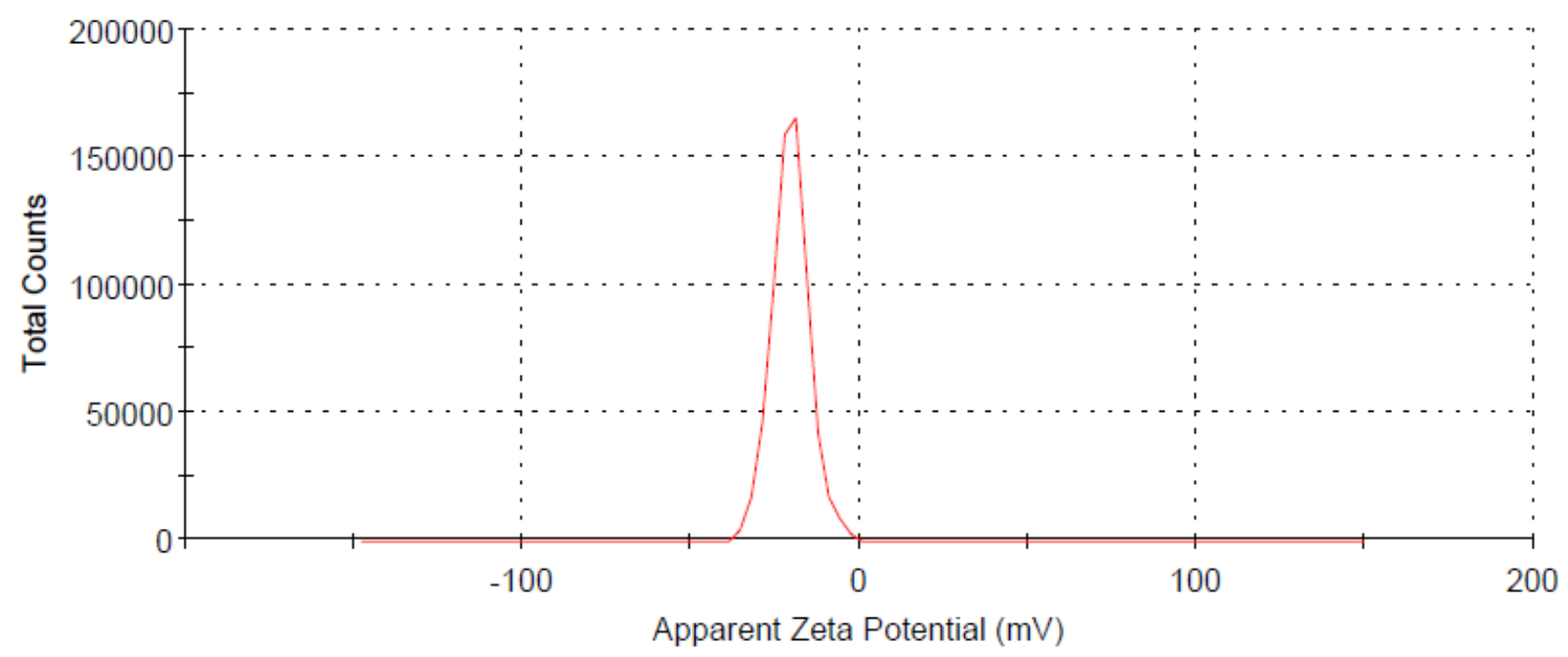

Fig. (9):Zeta potential of synthesized Ag-NPs byStreptomyces rochei strain MFA-37.

Assessment of AgNPssynergisticactivity in combination with antibiotics

In the current study, the efficacy of biosynthesized AgNPs alone and in combination with different antibiotics was studied against MDRS. aureus AS-185 and SA-325 clinical isolate using the disc diffusion method. Antibiotics used in this study belong to different groups and had different modes of action as indicated in the Table (3).

Generally, the Ag-NPs enhanced the antimicrobial activity of all tested antibiotics with a different degree for both organisms
(Table 3), where the Increase in fold area varied from one antibiotic to another. and also differ in both tested isolates, the increase varied from 0.15 to 6.37 -fold. There was an increase in antimicrobial activities of all antibiotics when combined with AgNPs. There was an increase in antimicrobial activities of all antibiotics when combined with AgNPs that suggests that these can enhance the activity of these antibiotics, which may be promising drugs for the treatment of MRSA infectious disease, especially the superficial injuries

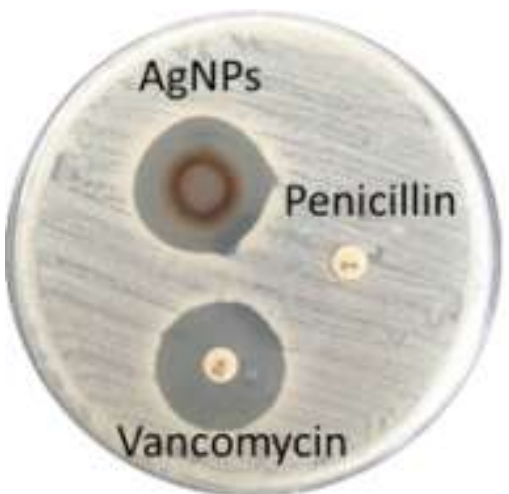

Fig. (10):Antibacterial activity of AgNPs, penicillin and vancomycin against MDRS. aureus SA-325. 
African J. Biol. Sci., 15 (1): 137-153 (2019)

ISSN 1687-4870

www.aasd.byethost13.com e- ISSN 2314-5501 (online)

e.mail: aasdjournal@yahoo.com
Interestingly, amongst the selected antibiotics, penicillin in combination with Ag-NPs showed the highest activity against two tested bacteria (Table 3). These results similar to the findings of Birla et al. (2009) who mentioned increasing efficacies (percentage) of antibiotics like vancomycin,
E. coli. Fayaz et al. (2010) assessed the antibacterial activities of ampicillin, chloramphenicol, erythromycin, and kanamycin combined with AgNPs against Gram-negative and Gram-positive bacteria, they concluded that the antibacterial activity of all antibiotics increased in the presence of

\section{Table 3: Screening of synergetic effect between antibiotics and AgNPs}

\begin{tabular}{|c|c|c|c|c|c|c|c|c|c|}
\hline \multirow{2}{*}{ Types of antibiotics } & \multirow{2}{*}{$\begin{array}{l}\text { Name of the } \\
\text { antibiotics }\end{array}$} & \multirow[b]{2}{*}{ code } & \multirow{2}{*}{$\begin{array}{c}\text { Potency } \\
(\mu \mathrm{g} / \mathrm{dis} \\
\mathrm{k})\end{array}$} & \multicolumn{3}{|c|}{ MRSA-185 } & \multicolumn{3}{|c|}{ MRSA-325 } \\
\hline & & & & a & $\mathrm{b}$ & $\mathrm{y}$ & a & $\mathrm{b}$ & $\mathrm{y}$ \\
\hline \multicolumn{10}{|c|}{ Inhibition of bacterial nucleic acid synthesis } \\
\hline \multirow{2}{*}{$\begin{array}{c}\text { FLUOROQUINOLONE } \\
\text { QUINOLONE } \\
\end{array}$} & Ciprofloxacin & CIP & 5 & $0(\mathrm{R})$ & 16 & 6.11 & $0(\mathrm{R})$ & 14 & 4.44 \\
\hline & Nalidixic acid & NA & 30 & $7(\mathrm{R})$ & 16 & 4.22 & $9(\mathrm{R})$ & 16 & 2.16 \\
\hline \multicolumn{10}{|c|}{ Inhibition of bacterial protein synthesis } \\
\hline \multirow{2}{*}{ AMINOGLYCOSIDES } & Gentamicin & $\mathrm{CN}$ & 10 & $8(\mathrm{R})$ & 15 & 2.5 & $0(\mathrm{R})$ & 15 & 5.25 \\
\hline & Neomycin & $\mathrm{N}$ & 30 & $14(\mathrm{R})$ & 15 & 0.15 & $0(\mathrm{R})$ & 14 & 4.44 \\
\hline MACROLIDES & Erythromycin & $\mathrm{E}$ & 15 & $0(\mathrm{R})$ & 16 & 6.11 & $0(\mathrm{R})$ & 13 & 3.69 \\
\hline TETRACYCLINES & Tetracycline & $\mathrm{TE}$ & 30 & $12(\mathrm{R})$ & 18 & 1.25 & $11(\mathrm{R})$ & 16 & 1.11 \\
\hline \multicolumn{10}{|c|}{ Inhibitors of bacterial cell wall synthesis } \\
\hline \multirow{3}{*}{ PENICILLINS } & Penicillin & $\mathrm{P}$ & $10 \mathrm{U}$ & $0(\mathrm{R})$ & 16 & 6.11 & $7(\mathrm{R})$ & 19 & 6.37 \\
\hline & Amoxicillin & $\mathrm{AX}$ & 25 & $12(\mathrm{R})$ & 18 & 1.25 & $8(\mathrm{R})$ & 20 & 5.25 \\
\hline & Oxacillin & $\mathrm{OX}$ & 1 & $0(\mathrm{R})$ & 15 & 5.25 & $0(\mathrm{R})$ & 12 & 3.0 \\
\hline
\end{tabular}

gentamycin, streptomycin, ampicillin, and kanamycin when used in combination with AgNPs against $P$. aeruginosa, $S$. aureus, and
AgNPs. Moreover, the highest synergistic effect was observed with ampicillin. 
Mahmoud A. Abushiba et al.

\begin{tabular}{|c|c|c|c|c|c|c|c|c|c|}
\hline & Methicillin & MET & 5 & $0(\mathrm{R})$ & 15 & 5.25 & $0(\mathrm{R})$ & 12 & 3.0 \\
\hline $\begin{array}{l}\text { PENICILLIN } \\
\text { COMBINATION }\end{array}$ & $\begin{array}{l}\text { Amoxicillin- } \\
\text { clavulanate }\end{array}$ & AMC & $20 / 10$ & $18(\mathrm{R})$ & 23 & 0.63 & $0(\mathrm{R})$ & 16 & 6.11 \\
\hline CEPHALOSPORINS & Cefoxitin & FOX & 30 & $0(\mathrm{R})$ & 15 & 5.25 & $0(\mathrm{R})$ & 13 & 3.69 \\
\hline CEPHALUSPUKINS & Cefuroxime & CXM & 30 & $7(\mathrm{R})$ & 13 & 2.44 & $0(\mathrm{R})$ & 16 & 6.11 \\
\hline \multicolumn{10}{|c|}{ Inhibitors of bacterial cytoplasmic membrane function } \\
\hline LIPOPEPTIDES & Polymyxin B & PB & $300 \mathrm{U}$ & $13(\mathrm{R})$ & 14 & 0.16 & $0(\mathrm{R})$ & 13 & 3.69 \\
\hline
\end{tabular}

In the absence of bacterial growth inhibition zones, the disc's diameter $(6 \mathrm{~mm})$ was used to calculate according to this equation: increase in fold area $=(\mathrm{b} 2-\mathrm{a} 2) / \mathrm{a} 2$. Mean diameter of inhibition zone of only AgNPs is $15.4 \mathrm{~mm}$.

\section{Conclusion}

This study represents an effective synthesis method of Ag NPs via greenway using cell-free filtrate of Streptomyces rochei strain MFA-37 as bio-reductant and capping agents. Physical characterization indicates that the biological synthesis of AgNPs in a crystalline form ranged in size 2 $20 \mathrm{~nm}$. The antibacterial activity of the particles was tested against multi-drug resistant $S$. aureus strains and showed high effectiveness against the tested bacteria. The combination of AgNPs with different antibiotics with a different mode of action was also screened and the study demonstrates the synergistic effect of antibiotics and nanoparticles which can be effectively used in order to improve their efficacy against $S$. aureus strains as a model of pathogenic microbes. AgNPs were found to be most effective with the antibiotics inhibiting cell wall synthesis followed by protein synthesis and nucleic acid synthesis against tested $S$. aureus strains. The feature of enhancement of the antibacterial potential of antibiotics using biosynthesized AgNPs can be utilized in the development of enhancement of antibiotic activity.

\section{Acknowledgments}

The authors are thankful to the Department of Microbiology, Ain shams University, Cairo, Egypt and to the Department of Botany and Microbiology, Al-Azhar University, Cairo, Egypt, for providing necessary laboratory facilities to execute these studies. The authors are very grateful to Microbiology laboratory, Tripoli University Hospital for providing the resistantS. aureusSA-185 and SA- 325 from clinical patients.Financial support: This work was supported by Azzaytuna University, Tarhuna, Libya and the Ministry of Education, Tripoli, Libya.

\section{REFERENCES}

Abd-Elnaby, H.M.; Abo-Elala, G.M.; AbdelRaouf, U.M. and Hamed, M.M. (2016). Antibacterial and anticancer activity of extracellular synthesized silver nanoparticles from marine Streptomyces rochei MHM13. Egypt. J. Aquat. Res., 42(3): 301-312. https://doi.org/10.1016/j.ejar.2016.05.00 4

Allahverdiyev, A.M.; Kon, K.V.; Abamor, E.S.; Bagirova, M. and Rafailovich, M. (2011). Coping with antibiotic resistance: combining nanoparticles with antibiotics and other antimicrobial agents. Expert Review of Anti-Infective Therapy, 9(11): 1035-1052.

Anandalakshmi, K.; Venugobal, J. and Ramasamy, V. (2016). Characterization of silver nanoparticles by green synthesis method using Pedalium murex leaf extract and their antibacterial activity. Appl. Nanosci., 6(3): 399-408.

Atta, H.M.; Bayoumi, R.; Sehrawi, M. and Galal, G.F. (2011). Taxonomic studies and phylogenetic Characterization of Streptomyces rimosus. KH-1223-55 isolated from Al-Khurmah Governorate, KSA. Researcher. 3.

Bauer, A.W.; Kirby, W.M.M.; Sherris, J.C. and Turck, M. (1966). Antibiotic 


\section{Enhancement of Antibiotics activity by microbially synthesized silver nanoparticles}

susceptibility testing by a standardized single disk method. American Journal of Clinical Pathology, 45(4_ts): 493-496.

Begum, N.A.; Mondal, S.; Basu, S.; Laskar, R. A. and Mandal, D. (2009). Biogenic synthesis of $\mathrm{Au}$ and $\mathrm{Ag}$ nanoparticles using aqueous solutions of Black Tea leaf extracts. Colloids and Surfaces B: Biointerfaces, 71(1): 113-118.

Bhosale, R.S., Hajare, K.Y.; Mulay, B.; Mujumdar, S. and Kothawade, M. (2015). Biosynthesis, characterization and study of antimicrobial effect of silver nanoparticles by Actinomycetes spp. Int. J. Curr. Microbiol. Appl. Sci, 2: 144-151.

Birla, S.S.; Tiwari, V.V.; Gade, A.K.; Ingle, A.P.; Yadav, A.P. and Rai, M.K. (2009). Fabrication of silver nanoparticles by Phoma glomerata and its combined effect against Escherichia coli, Pseudomonas aeruginosa and Staphylococcus aureus. Letters in Applied Microbiology, 48(2): 173-179.

Borase, H. P., Patil, C. D., Salunkhe, R. B., Narkhede, C. P., Salunke, B. K., \& Patil, S. V. (2013). Phyto-synthesized silver nanoparticles: a potent mosquito biolarvicidal agent. J Nanomedine Biotherapeutic Discov, 3(1), 1-7.

Daini, O. A. and Akano, S.A. (2009). Plasmidmediated antibiotic resistance in Staphylococcus aureus from patients and non patients. Scientific Research and Essays, 4(4): 346-350.

Daphedar, A. and Taranath, T.C. (2018). Characterization and cytotoxic effect of biogenic silver nanoparticles on mitotic chromosomes of Drimia polyantha (Blatt. \& McCann) Stearn. Toxicology Reports, 5: 910-918.

Deepa, S.; Kanimozhi, K. and Panneerselvam, A. (2013). Antimicrobial activity of extracellularly synthesized silver nanoparticles from marine derived actinomycetes. Int. J. Curr. Microbiol. Appl. Sci., 2(9): 223-230.

El-Naggar, N.E.-A.; Mohamedin, A.; Hamza, S.S. and Sherief, A.-D. (2016). Extracellular biofabrication, characterization, and antimicrobial efficacy of silver nanoparticles loaded on cotton fabrics using newly isolated Streptomyces sp. SSHH-1E. Journal of Nanomaterials, 2016.

Fayaz, A.M.; Balaji, K.; Girilal, M.; Yadav, R.; Kalaichelvan, P.T.; Venketesan, R. (2010). Biogenic synthesis of silver nanoparticles and their synergistic effect with antibiotics: a study against grampositive and gram-negative bacteria. Nanomedicine: Nanotechnology, Biology and Medicine, 6(1): 103-109.

Golinska, P.; Wypij, M.; Ingle, A.P.; Gupta, I.; Dahm, H. and Rai, M. (2014). Biogenic synthesis of metal nanoparticles from actinomycetes: biomedical applications and cytotoxicity. Appl. Microbiol. Biotechnol., 98(19): 8083-8097.

Hensyl, W.R. (1994). Bergey's Manual of systematic bacteriology 9th Edition. John. G. Holt and Stanley, T. Williams (Eds.) Williams and Wilkins Baltemor, Philadelphia, Hong Kong, London Munich, Sydney, Tokyo.

Holt, J.G.; Krieg, N.R.; Sneath, P.H.A.; Staley, J.T. and Williams, S.T. (1994). Bergey's manual of determinative bacteriology. 9th. Baltimor: William \& Wilkins.

Iram, S.; Nadhman, A.; Akhtar, N.; Hameed, A.; Zulfiqar, Z. and Yameen, M.A. (2015). Potentiating efficacy of antibiotic conjugates with zinc oxide nanoparticles against clinical isolates of Staphylococcus aureus. Dig J Nanomater Biostructure, 10(3): 901914.

Jinmeng Li; Qinqin Ma; Huanhuan Shao; Xia Zhou; Hongmei Xia and J. X. (2017). Biosynthesis, Characterization, and Antibacterial Activity of Silver Nanoparticles Produced from Rice Straw Biomass. 12(3): 4897-4911.

Karthik, L.; Kumar, G.; Kirthi, A.V.; Rahuman, A.A. and Rao, K.V.B. (2014). Streptomyces sp. LK3 mediated synthesis of silver nanoparticles and its biomedical application. Bioprocess and Biosystems Engineering, 37(2), 261267. 


\section{Mahmoud A. Abushiba et al.}

Kumar, P. S.; Balachandran, C.; Duraipandiyan, V.; Ramasamy, D.; Ignacimuthu, S. and Al-Dhabi, N. A. (2015). Extracellular biosynthesis of silver nanoparticle using Streptomyces sp. 09 PBT 005 and its antibacterial and cytotoxic properties. Applied Nanoscience, 5(2): 169-180.

Lakshmi, P.T.V.; Priyanka, D. and Annamalai, A. (2015). Reduction of Silver Ions by Cell Free Extracts of Westiellopsis sp. Int. J. Biomaterials, 2015.

Li, P., Li, J.; Wu, C.; Wu, Q. and Li, J. (2005). Synergistic antibacterial effects of $\beta$ lactam antibiotic combined with silver nanoparticles. Nanotechnol., 16(9): 1912.

Majeed, S.; bin Abdullah, M.S.; Nanda, A. and Ansari, M.T. (2016). In vitro study of the antibacterial and anticancer activities of silver nanoparticles synthesized from Penicillium brevicompactum (MTCC1999). J. Taibah Univ. for Science, 10(4): 614-620.

Manikprabhu, D. and Lingappa, Kjj. (2013). Antibacterial activity of silver nanoparticles against methicillinresistant Staphylococcus aureus synthesized using model Streptomyces sp. pigment by photo-irradiation method. J. Pharm. Res., 6(2): 255-260.

Moghannem, S. A. M.; El-sherbiny, G. M. and Kalaba, M. H. (2017). Isolation and Identification of Streptomyces Baarnensis Mh-133 Produce Bioactive Metabolite Inhibiting Multidrug Resistant Bacteria (Mdrb). 3(6): 64-75.

Mohamedin, A.; El-Naggar, N.E.-A.; Shawqi Hamza, S. and Sherief, A. A. (2015). Green synthesis, characterization and antimicrobial activities of silver nanoparticles by Streptomyces viridodiastaticus $\mathrm{SSHH}-1$ as a living nanofactory: statistical optimization of process variables. Current Nanoscience, 11(5): 640-654.

Narasimha, G.; Janardhan, A.; Alzohairy, M.; Khadri, H. and Mallikarjuna, K. (2013). Extracellular synthesis, characterization and antibacterial activity of Silver nanoparticles by Actinomycetes isolative. International Journal of Nano
Dimension, 4(1): 77-83.

Phanjom, P. and Ahmed, G. (2015). Biosynthesis of silver nanoparticles by Aspergillus oryzae (MTCC No. 1846) and its characterizations. Nanoscience and Nanotechnology, 5(1): 14-21.

Raut Rajesh, W.; Lakkakula Jaya, R.; Kolekar Niranjan, S.; Mendhulkar Vijay, D. and Kashid Sahebrao, B. (2009). Phytosynthesis of silver nanoparticle using Gliricidia sepium (Jacq.). Current Nanoscience, 5(1): 117-122.

Saha, S.; Sarkar, J.; Chattopadhyay, D.; Patra, S.; Chakraborty, A. and Acharya, K. (2010). Production of silver nanoparticles by a phytopathogenic fungus Bipolaris nodulosa and its antimicrobial activity. Dig J Nanomater Biostruct, 5(4): 887-895.

Singh, M.; Kumar, M.; Kalaivani, R.; Manikandan, S. and Kumaraguru, A. K. (2013). Metallic silver nanoparticle: a therapeutic agent in combination with antifungal drug against human fungal pathogen. Bioprocess and Biosystems Engineering, 36(4): 407-415.

Składanowski, M.; Wypij, M.; Laskowski, D.; Golińska, P.; Dahm, H. and Rai, M. (2017). Silver and gold nanoparticles synthesized from Streptomyces sp. isolated from acid forest soil with special reference to its antibacterial activity against pathogens. J. Cluster Science, 28(1): 59-79.

Tsao, P. H.; Leben, C. and Keitt, G.W. (1960). An enrichment method for isolating Actinomycetes that produce diffusible antifungal antibiotics. Phytopathology, 50(1): 88-89.

Zarina, A. and Nanda, A. (2014). Combined efficacy of antibiotics and biosynthesized silver nanoparticles from Streptomyces albaduncus. Int $\mathbf{J}$ PharmTech Res, 6, 1862-1869.

Zonooz, N. F., \& Salouti, M. (2011). Extracellular biosynthesis of silver nanoparticles using cell filtrate of Streptomyces sp. ERI-3. Scientia Iranica, 18(6): 1631-1635. 


\title{
Enhancement of Antibiotics activity by microbially synthesized silver nanoparticles
}

\author{
تعزيز نثاط المضادات الحيوية بواسطة جسيمات الفضة النانوية المخلقة ميكروبيا

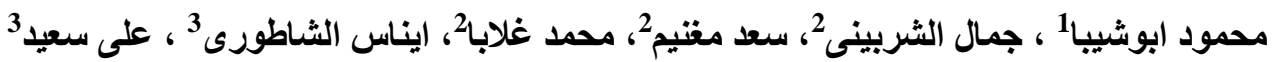

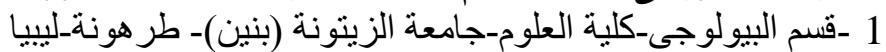

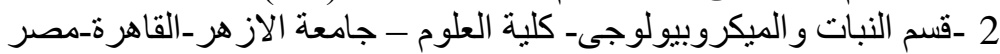

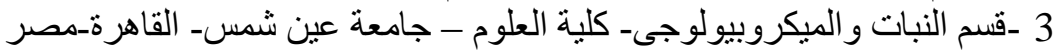

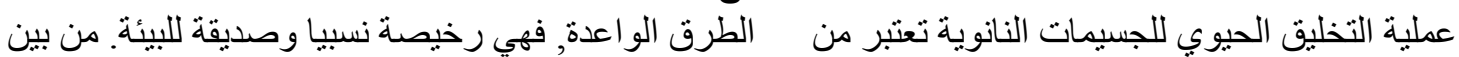

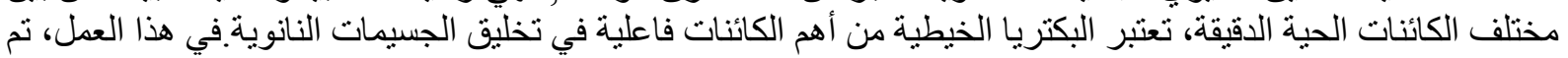

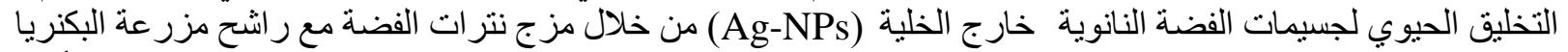

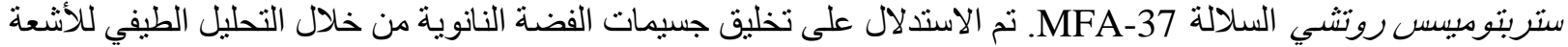
المرئية و الفوق البنفسجية ( UV-Vis spectrum)، حيث أظهرت المزيج ذروة امتصاص عند الطول الموجي 440 نانومتر.

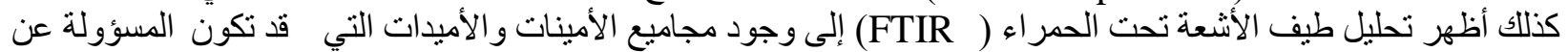

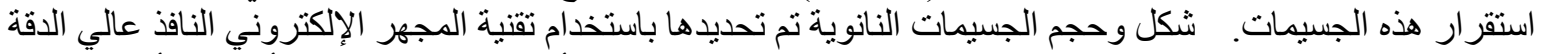

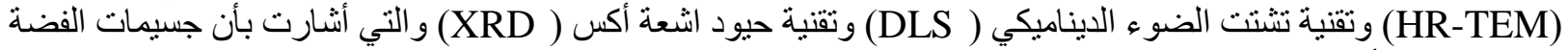

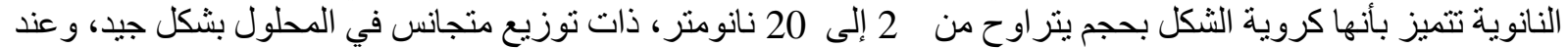

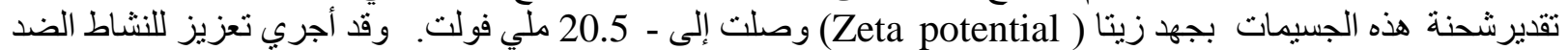

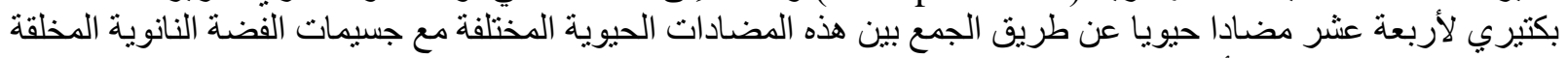

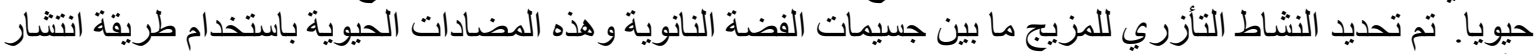
الأقر اص على الاجار ضد الثيل الثين من سلالات المكور ات العنقودية الذهبية المقاومة للادويه المتعددة

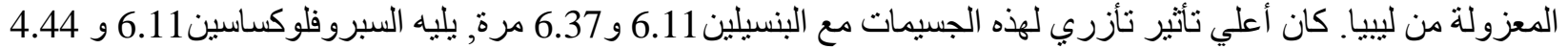

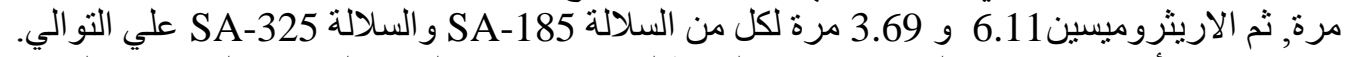

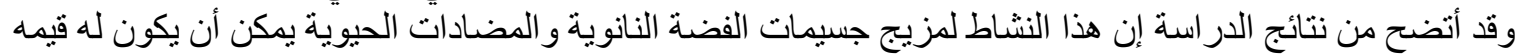

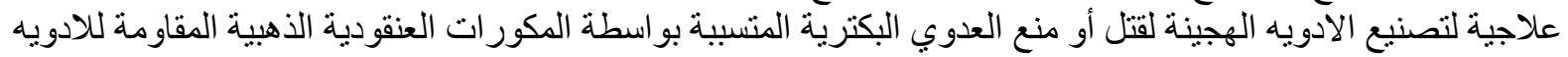
المتعددة خاصه في حاله الإصابات السطحية. 